\title{
Quem é seu melhor professor universitário e por quê? Características do bom professor universitário sob o olhar de licenciandos
}

\author{
Graziela Giusti Pachane*
}

\section{Resumo}

A presente pesquisa objetiva analisar a percepção de alunos de diferentes cursos de licenciatura de uma universidade de Minas Gerais a respeito das características do bom professor universitário. Conduzida a partir de dados levantados para elaboração de um trabalho de conclusão de uma disciplina de graduação, o estudo foi ampliado e incorporado a um projeto mais amplo, que visa analisar questões relativas à pedagogia universitária. Tendo por base estudos realizados por pesquisadores nacionais e internacionais acerca da formação pedagógica e do trabalho do professor universitário, foram analisados os dados obtidos a partir do questionário criado para conhecer quem eram os melhores professores na visão dos licenciandos e por que razão eles se distinguiam. Os resultados apontam para a importância da didática, do bom relacionamento pessoal com os alunos, do domínio aprofundado do conteúdo, das habilidades de comunicação e da preocupação com a aprendizagem dos estudantes como os fatores que se sobressaem na caracterização dos bons professores universitários, segundo a percepção destes licenciandos. Abrem, ainda, oportunidade a uma série de questionamentos, muitos deles acerca do papel desses professores, por sua vez formadores de formadores.

Palavras-chave: docência universitária, licenciaturas, professores universitários.

\section{Who is your best university teacher and why? characteristics of good university teachers under the view of teacher education students}

\section{Abstract}

This text aims to analyze the perception of students from different teaching courses at a Federal University in Minas Gerais about the characteristics of good university teachers. It amplifies the analysis developed by a group of graduate students who collect data for a report written as final task of a graduate discipline. This previous report was introduced in a larger project whose objective was to study university pedagogy. Based on studies conducted by national and international researchers on university teachers' education and practice, we analyzed the data collected by means of a questionnaire specifically designed

\footnotetext{
* Professora Doutora Adjunta da Universidade Federal do Triângulo Mineiro (UFTM), Uberaba, Minas Gerais, Brasil.
} 


\section{Graziela Giusti Pachane}

to know who were considered the best professors, and why they were distinguished from others, according to the opinion of teaching students. The results of the research points out the importance of didactics, of good relationship with students, specific content knowledge, communication abilities and concern with students' learning as the main important factors that distinguish the best teachers from others. Results also lead us to a number of questions, mainly related to the fact that those teachers are responsible for preparing other teachers.

Keywords: university teaching, teaching education courses, university teachers.

\section{Introdução}

Os resultados desta pesquisa tiveram início no trabalho desenvolvido por cinco alunos ingressantes nos cursos de licenciatura e serviço social de uma universidade federal de Minas Gerais, no decorrer da disciplina Estudos e Desenvolvimento de Projetos, sob minha orientação. O trabalho idealizado por este grupo tinha por objetivo fazer um levantamento da percepção de alunos da mesma universidade sobre as características do bom professor universitário.

Baseando-se em trabalhos anteriores realizados por Pimentel (1993), Cunha (1989; 1998), Pimenta e Anastasiou (2002), Pachane (2007) e Leite (2010), entre outros, foi elaborada a revisão bibliográfica e, a partir dela, um questionário composto por três perguntas: 1) quem você considerada o(a) seu(sua) melhor professor(a) na Universidade; 2) qual a disciplina que ele(a) ministrou; e 3) quais características fazem dele(a) um(a) bom(boa) professor(a). Foi também pedido aos respondentes que indicassem seu curso e o período que cursavam.

Após elaboração de um questionário piloto, o instrumento final foi aplicado durante as aulas, mediante autorização dos professores responsáveis pelas turmas visitadas. Foram considerados para análise 76 questionários de alunos de diversas licenciaturas cursando entre o segundo e quinto período. Devido à qualidade dos dados levantados, bem como ao empenho da equipe, o trabalho foi incorporado a um projeto maior, que visa analisar questões relativas à pedagogia universitária. Submetido a análises complementares, constituiu-se na base sobre a qual se sustenta o presente artigo.

Seus resultados apontam para a importância da didática do professor, do relacionamento pessoal com os estudantes, do domínio aprofundado do conteúdo específico, das habilidades de comunicação e da preocupação com a efetiva aprendizagem dos alunos como os itens que mais se sobressaem ao elaborarmos o perfil de um bom professor universitário sob o olhar dos licenciandos. Os resultados permitem, ainda, o levantamento de uma série de novos questionamentos, com convite à continuidade dessa discussão. 


\section{O olhar da literatura acerca do bom professor universitário}

Cada autor, ao tratar das características dos bons professores universitários, apresenta um conjunto diferenciado de elementos, em algumas classificações, mais sintetizado, apresentando categorias genéricas, enquanto em outras trazem elementos bastante detalhados.

Para Benedito, Ferrer e Ferreres (1995), o professor universitário é um profissional que realiza um serviço à sociedade através da universidade e deve, para tanto, ser reflexivo, crítico, competente no âmbito de sua disciplina, capacitado para exercer a docência e para realizar atividades de pesquisa. Deve tentar desenvolver uma atividade docente comprometida com a ideia de potencializar a aprendizagem dos estudantes e contribuir com a melhoria da sociedade, buscando que o conhecimento construído nas aulas, workshops e laboratórios seja relevante para a formação teórica e prática dos estudantes. Segundo os autores, deverá, ainda, preparar os alunos para que estes possam, cada vez com mais autonomia, avançar em seus processos de estudo e na interpretação crítica do conhecimento e da sociedade ao passo que adquirem uma capacitação profissional.

Marcelo García (1999, p. 93) salienta que, em geral, na tentativa de estabelecer-se um perfil desejável de professores universitários, levam-se em conta as dimensões: cognitiva (níveis de pensamento promovidos nos alunos), socioemocional (críticas, elogios, iniciação, resposta), substantiva (conteúdo das aulas), e comunicativa (linguagem, clareza, fluidez, expressividade). Acrescenta que, além dos conhecimentos específicos, os professores têm de desenvolver habilidades de conduta e cognitivas: capacidade de avaliação, resolução de conflitos, análise do contexto, além da compreensão, perante a diversidade cultural, de aspectos do currículo oculto e do currículo em ação. Assim, no que diz respeito aos níveis e componentes do conhecimento profissional dos docentes, o autor entende que os professores deveriam ter desenvolvidas as seguintes dimensões: 1) conhecimento psicopedagógico; 2) conhecimento de conteúdo; 3) conhecimento didático do conteúdo e 4) conhecimento do contexto.

No estudo acerca do que os professores universitários deveriam conhecer, Sarah Dinham destaca que o conhecimento do professor deve incluir não apenas o conteúdo a ser ensinado, mas também a "habilidade para refletir profundamente sobre o ensino assim como para agir habilmente" (DINHAM, 1996, p. 297). A seguir, ressalta que o professor necessita ter conhecimento dos estudantes como aprendizes, conhecimento sobre o ensino, conhecimento da disciplina (sua substância, seu caráter, sua forma, sua lógica e sua epistemologia), conhecimento sobre o ensino específico da disciplina (didática da disciplina), conhecimento do contexto e conhecimento de si mesmo como professor. 


\section{Graziela Giusti Pachane}

Para Pimenta e Anastasiou (2002, p. 103-104), a prática docente na universidade pressupõe o domínio de um conjunto de conhecimentos, métodos e técnicas que devem ser ensinados criticamente (isto é, em seus nexos com a produção social e histórica da sociedade); a condução a uma progressiva autonomia do aluno na busca de conhecimentos; o desenvolvimento da capacidade de reflexão; a habilidade de usar documentação com domínio científico e profissional do campo específico. Pressupõe, também, considerar o processo de ensinar e aprender como atividade integrada à investigação e a necessidade de saber trabalhar em equipe. Acrescentam que o professor deve buscar criar e recriar situações de aprendizagem; valorizar a avaliação diagnóstica e compreensiva da atividade mais do que a avaliação como controle; procurar conhecer o universo cognitivo e cultural dos alunos e, com base nisso, desenvolver processos de ensino e aprendizagem interativos e participativos.

As autoras complementam que essas características do ensinar requerem, além de preparação nas áreas dos conhecimentos específicos e pedagógicos, opções éticas, compromissos com os resultados do ensino, sensibilidade e sabedoria dos professores. Consideram que os professores devem ser capazes de construir um tipo especial de profissionalismo, no qual: a) promovam um aprendizado cognitivo profundo; b) sejam comprometidos com uma aprendizagem profissional contínua; c) aprendam a ensinar de modo diferente de como foram ensinados por seus antigos mestres; $d$ ) trabalhem e aprendam com seus pares (em grupos); e) desenvolvam a capacidade de mudar, arriscar e pesquisar; f) construam, nas instituições educativas, organizações de aprendizagem.

Portanto, além do componente cognitivo, intelectual, os professores da sociedade da informação devem, a seu ver, possuir também aspectos sociais, emocionais, afetivos. Daí serem considerados como elementos de resistência a essa sociedade. Como tais, devem promover a aprendizagem e o comprometimento social e emocional; comprometer-se com o desenvolvimento contínuo tanto do aspecto profissional quanto do pessoal; aprender a se relacionar, construindo ligações fortes e duradouras com as pessoas, e trabalhar e aprender em grupos cooperativos (PIMENTA; ANASTASIOU; p. 188-189, 2002).

Pensando especificamente na avaliação do trabalho docente, o Forgrad - Fórum de Pró-Reitores de Graduação das Universidades Brasileiras, após uma série de discussões, elaborou em 2002 um documento no qual considera que se faz necessário construir processos avaliativos que tenham presentes "elementos que possam retratar aspectos didático-metodológicos, a compreensão do professor sobre o seu trabalho, a relação das disciplinas trabalhadas por ele com as demais do curso e objetivos do conteúdo eleito, entre outros" (FORGRAD, apud RODRIGUES, 2002).

Assim, além de indicativos que diziam respeito mais especificamente a atividades de pesquisa, extensão e gestão (como participar de grupos de pesquisa, participar de grupos sociais e comunitários, produção acadêmica, 
etc.), e mesmo titulação, o Forgrad propunha que, ao se avaliar a qualidade do trabalho docente, fossem levados em conta outros indicativos, a partir dos quais podemos imaginar o perfil de bom professor idealizado pelo Fórum: atitudes éticas; capacidade de adaptação a mudanças; capacidade de trabalho em grupo e relacionamento interpessoal; compatibilidade de formação com as atividades curriculares desenvolvidas; criatividade; dedicação; efetividade do professor; compromisso com a Instituto de Ensino Suerior (IES); habilidades didáticopedagógicas; capacidade de negociação e organização didática; manejo de informações; frequência, aproveitamento; atendimento extraclasse, relacionamento professor-aluno; sólida formação científica na área específica/ pedagógica/ humanística e cultural.

Também Chauí (2001, p. 148-150), ao tratar da necessidade de que a docência seja avaliada por critérios diferentes dos atuais, elabora uma lista com a sugestão de algumas questões que poderiam balizar a definição da qualidade da docência. Segundo a autora, para iniciar o debate, poderiam ser feitas as seguintes perguntas: os professores variam os conteúdos de seus cursos, preparam suas aulas, pesquisam para novos cursos, introduzem novas questões para os alunos, exigem pesquisa dos estudantes, transmitem os clássicos de sua área, as principais questões e impasses, as inovações mais significativas? Ou prevalecem rotina, repetição, pouca exigência para avaliação dos alunos, pouco conhecimento dos clássicos da área e dos principais problemas e inovações da área? Os cursos são capazes de mesclar e equilibrar informação e formação? Os estudantes são iniciados, por meio do tipo de aula e do método de trabalho do professor, ao estilo acadêmico, ou não? Qual a bibliografia usada? Como o estudante é introduzido ao trabalho de campo e ao laboratório? Como o professor e os alunos enfrentam a precariedade do segundo grau quanto a informações e desconhecimento de línguas estrangeiras? Que tipos de trabalhos são exigidos dos alunos?

A seguir, a autora acrescenta que, entre outros aspectos, a docência excelente seria aquela que: a) inicia os estudantes aos clássicos, aos problemas e às inovações da área; b) varia e atualiza cursos, bibliografia, aproveitando os trabalhos de pesquisa que o professor está realizando (para uma tese, um livro ou um artigo); c) inicia ao estilo e às técnicas próprias da área; d) informa e forma novos professores ou profissionais não-acadêmicos da área; e) leva os estudantes ao aprendizado de outras línguas e consegue que os departamentos de línguas Ihes ofereçam cursos; f) luta por condições de infraestrutura para os estudantes - biblioteca, laboratórios, computadores, instrumentos de precisão, veículos para trabalhos de campo etc.; g) exige trabalhos escritos e orais contínuos dos estudantes, oferecendo-lhes uma correção explicativa de cada trabaIho realizado, de tal modo que cada novo trabalho possa ser melhor do que 0 anterior, graças a correções, observações e sugestões do professor; $h$ ) o professor incentiva os diferentes talentos, sugerindo trabalhos que, posteriormente, auxiliarão o estudante a optar por uma área de trabalho acadêmico, ou uma área de pesquisa ou um aspecto da profissão escolhida e que será exercida logo 


\section{Graziela Giusti Pachane}

após a graduação - em suma, a docência que forma novos docentes, incentiva novos pesquisadores e prepara profissionalmente para atividades não-acadêmicas (CHAUÍ, 2001, p. 149-150).

Finalizamos o olhar da literatura a respeito das características do bom professor com Maria Isabel Cunha (1998, p. 97-99) que, ao tratar do professor universitário na transição de paradigmas, aponta a necessidade de que o professor respeite e valorize o conhecimento que o aluno traz, entenda o erro como parte integrante do processo de aprender, resgate o prazer do aprender, busque envolver o aluno na produção de conhecimento e na elaboração de trabalhos coletivos, desenvolva seu trabalho a partir da integração entre ensino-pesquisa e da relação teoria-prática, buscando implementar a reflexão e discussão de problemas reais, entenda que os conhecimentos produzidos são apenas sínteses provisórias e não a "verdade definitiva sobre os fatos", ajude a promover a interdisciplinaridade - ou, em suas palavras, "que cada ciência, para se configurar como significativa, tem de se deixar penetrar por outras áreas e formas de conhecimento" -, e busque novas formas de organizar seu ensino e de realizar o processo de avaliação.

A autora enfatiza, ainda, a necessidade de que o professor promova a vinculação dos conteúdos acadêmicos com o contexto histórico-político-social mais amplo, possua conhecimento da história de sua área científica, sabendo identificar motivações e interesses que foram definidores do conhecimento através dos tempos; e promova a interpretação dos fatos da atualidade ligando-os ao seu campo científico e aos compromissos com a cidadania.

São características que ultrapassam, e muito, o domínio do conteúdo, as habilidades de comunicação e de relacionamento pessoal como citado por Pachane (2009, p. 264) ao discutir o perfil necessário aos professores universitários diante dos desafios de um mundo em transformação.

\section{O olhar dos licenciandos acerca do bom professor universitário}

Dentre os 76 questionários considerados válidos, 31 são do curso de História, 20 do curso de Química, 16 de Geografia, e 9 dos cursos de Física, Matemática e Ciências Biológicas (três de cada um). Os respondentes são 15 do segundo período (semestre), 19 do terceiro e 42 do quarto período. O número de questionários válidos corresponde a aproximadamente $15 \%$ do total do corpo discente dos cursos analisados, excetuando-se os primeiros períodos, que não foram considerados para análise. Devido à maneira como os questionários foram obtidos (mediante autorização dos docentes para que pudéssemos aplicálos durante suas aulas), não foi possível obter uma amostragem estratificada.

Dos questionários respondidos, 39 citaram como seus melhores professores docentes os que não lecionam disciplinas de conteúdo específico de suas áreas de formação (pouco mais de $50 \%$ do total). Por não termos um número representativo dos diferentes cursos, não podemos dizer se há predomi- 
nância de escolha de professores de áreas específicas em determinados cursos e outros não. Mesmo a separação por grande área do conhecimento não nos permite generalizações. Temos apenas 29 respondentes das Ciências Exatas e Naturais e 47 de Ciências Humanas, assim, não nos apressaremos em uma conclusão acerca da predominância de docentes da área de humanidades com características mais próximas àquelas consideradas como de bons professores, embora os números nesta amostragem apontem para esta tendência.

A análise da questão aberta se deu a partir de pressupostos da Análise de Conteúdo (BARDIN, 2008; FRANCO, 2005), buscando integrar elementos quali e quantitativos. A distribuição dos itens citados pelos respondentes se deu na organização descrita a seguir:

\begin{tabular}{|c|c|}
\hline CARACTERÍSTICA DO PROFESSOR & $\begin{array}{c}\text { N. DE } \\
\text { CITAÇÕES }\end{array}$ \\
\hline Boa didática & 25 \\
\hline Domínio do conteúdo & 23 \\
\hline Boa relação interpessoal com aluno & 22 \\
\hline Clareza nas explicações & 20 \\
\hline Preocupa-se com a aprendizagem do aluno & 19 \\
\hline Aulas dinâmicas & 13 \\
\hline Clima envolvente das aulas & 12 \\
\hline Rigor e disciplina & 8 \\
\hline Modo de avaliação & 7 \\
\hline Organização e objetividade & 7 \\
\hline Envolvimento e comprometimento com o fazer docente & 7 \\
\hline Aula desenvolve o raciocínio e a reflexão & 6 \\
\hline Sabe conduzir discussões & 6 \\
\hline Postura flexível & 6 \\
\hline Paciente & 5 \\
\hline Habilidades de comunicação & 5 \\
\hline
\end{tabular}




\section{Graziela Giusti Pachane}

Além destes itens, com quatro citações tivemos: estabelece relações com o cotidiano, estabelece relação teoria-prática. Com três referências: promove conhecimento do aluno, leciona em áreas que o aluno gosta, sabe usar variedade de recursos pedagógicos, tem bom relacionamento extraclasse, é pontual e assíduo.

A seguir, com somente duas referências: sabe explorar o potencial do aluno, não deixa dúvidas, motiva o aluno a buscar respostas a suas dúvidas, planeja, faz boa seleção de conteúdos e textos, é imparcial e justo, é aberto ao diálogo, é bem-humorado, tem competência profissional ou de pesquisa, explora atividades extrassala, tem disponibilidade para atendimento ao aluno. Por fim, com uma referência apenas: é inteligente, simples, humilde, simpático e tem amplo conhecimento geral.

Após a tabulação dos dados, pudemos observar que boa didática se sobressai, porém, a fim de tentarmos compreender a que os alunos se referem quando mencionam boa didática, há necessidade de nos aprofundarmos num estudo dos demais itens levantados.

Os licenciandos compreendem que, para ser um bom professor, há necessidade de conhecimento específico do conteúdo (23) e, como muito destacado por eles, segurança na hora da exposição. Além disso, os dados nos permitem concluir que, para muitos, a qualidade do professor se relaciona diretamente com "saber passar o conteúdo", tanto que clareza na exposição figura em quarto lugar em nossa classificação. Porém, se aliado ao item habilidade de comunicação (que destaca aspectos como desenvoltura), somam-se 25 citações referentes ao professor claro, assertivo, enfim, bom comunicador.

Ao analisarmos estes itens conjuntamente com dinâmica da aula (13) e saber utilizar variedade de recursos pedagógicos (3), vamos sentindo, cada vez mais, que o bom professor, na visão do aluno, é o bom expositor, um mediador que consegue "traduzir" o conhecimento de forma clara e objetiva para o aluno. Isso se explica pois a aula dinâmica não implica para eles, necessariamente, participação ativa do aluno, mas, mais fortemente, aquela que consegue "prender sua atenção", que não é dispersiva ou monótona. Também o item saber utilizar variedade de recursos pedagógicos trazia, na resposta de um dos alunos, a ideia de "saber utilizar os slides como suporte para sua aula e não como material de leitura".

A esse respeito, chamou-nos a atenção o fato de que seis alunos destacaram a característica de saber conduzir uma discussão. Pela análise qualitativa das respostas enquadradas neste item, pudemos concluir que aulas mais abertas ao diálogo, nas quais há espaço para discussão, para as vozes dos alunos, pode levar à dispersão em sala ("fugir do tema da aula"). Assim, observamos que estes licenciandos preferem uma boa aula tradicional e expositiva a uma aula dinâmica e participativa, porém propensa à dispersão. 
Aprofundando um pouco mais nessa questão, tentando ainda compreender o que os alunos consideram como ter uma boa didática, temos, com 12 citações, o item faz uma aula envolvente. Dentro desse item, os alunos mencionam o fato de o professor ser capaz de motivar, provocar, instigar, prender a atenção do aluno. Em uma das respostas obtidas, um aluno chega a mencionar o "magnetismo pessoal" do professor por ele considerado o melhor. Outro diz que o professor era capaz de "criar uma atmosfera intelectualmente estimulante". Um último: "que o professor era capaz de entusiasmar tanto os alunos que ele passou a gostar de um conteúdo que anteriormente não gostava".

Um dos aspectos que, a nosso ver, está intimamente relacionado à didática do professor foi mencionado por um número muito pequeno de alunos: o planejamento. Apenas dois se referiram à importância do professor planejar suas aulas. Por outro lado, sete referiram como fatores positivos dos professores o quesito organização e objetividade.

Pela análise qualitativa das respostas, percebemos que o aluno se sente mais seguro quando o professor estabelece datas, prazos, quando apresenta seu planejamento para o semestre ou para a aula, quando conduz suas aulas, e mesmo a exposição, com uma coerência lógica, sem dispersões ou digressões ou sem mudanças repentinas de rumos. Até da resolução de exercícios os alunos cobram esta organização e objetividade, reclamando de professores que não realizam demonstrações passo a passo de um processo ou da resolução de um problema matemático.

Surpreendeu-nos o fato de apenas dois alunos mencionarem a habilidade do professor ao selecionar conteúdos e textos que sejam significativos e compreensíveis pelos alunos. Em nossa prática cotidiana, temos muito contato com as reclamações dos alunos acerca da dificuldade de compreensão das leituras pedidas pelos docentes, bem como da incompreensão de sua importância no contexto geral de aprendizagem. De nossa amostragem, o item que mais diretamente se reporta a este fato é o relacionado a saber conduzir uma discussão, quando alguns alunos mencionaram o fato de o professor saber trabalhar os textos lidos em aula, "provocando realmente uma reflexão sobre eles e não apenas cobrando o fichamento". Porém, ainda assim, limitam-se ao modo como o professor trabalha a partir do texto e não diretamente a sua seleção.

Dessa forma, a partir do material que temos em mãos, não podemos afirmar se os bons professores citados sabem escolher seu material de leitura, se sabem como trabalhar com esses materiais apesar de sua complexidade ou se os estudantes já naturalizaram que os textos são difíceis e cabe ao professor "traduzi-los" para os alunos, como citado anteriormente. Também ficamos com uma questão em aberto e que diz respeito à compreensão - ou não - por parte destes licenciandos de que o planejamento de uma aula faz parte do trabalho cotidiano do professor, estando relacionado à didática. 


\section{Graziela Giusti Pachane}

Em termos de conteúdo estudado, apenas quatro alunos mencionaram que seus professores se destacaram ao proporcionar a relação do conteúdo estudado com o cotidiano (contexto social mais amplo), e outros quadro ao proporcionar a relação teoria-prática. Isso pode se dever ao fato de a relação teoria-prática e com o cotidiano do aluno sejam princípios que fundamentam a proposta pedagógica na qual estes cursos estão inseridos. Assim, fazer a relação de seu conteúdo específico com o cotidiano e com a prática não seria uma característica distintiva entre estes professores, embora seja um item bastante presente em outros estudos (PACHANE, 2007, p. 167).

No que diz respeito à avaliação, sete alunos mencionaram que os bons professores, a seu ver, sabiam realizar avaliações instigantes, inovadoras, que abrangiam práticas variadas e que levavam os alunos a mostrar o seu meIhor, em síntese, avaliações que buscavam, de variadas formas, levantar o que o aluno aprendeu e, por outro lado, proporcionavam aprendizagem.

Pudemos constatar, da parte inicial desta análise, que muitos alunos relacionaram a didática e o ser bom professor ao fato de o docente ser um bom expositor de conteúdo, um facilitador da compreensão pelo aluno. Ou seja, ele é o grande protagonista do ato de ensinar. No entanto, a já muito discutida relação entre ensinar e aprender (ANASTASIOU e ALVES, 2003, por exemplo); apareceu no conjunto de questionários analisados, embora em tons ainda bastante modestos.

Para 17 de nossos respondentes, o bom professor é aquele que efetivamente se (pre)ocupa com a aprendizagem do aluno, com o seu acompanhamento, com um olhar atento a seu desenvolvimento, a suas dúvidas, e "busca saná-las todas" (citado por dois alunos, numa visão bastante tradicional e até, podemos dizer, paternalista), ou promover a autonomia para que o aluno busque, ele mesmo, encontrar caminhos para responder a seus questionamentos (citado também por dois alunos, numa visão já mais próxima à ideia de construção de conhecimentos e ao desenvolvimento da autonomia do estudante).

A relação ensino-aprendizagem transparece também no momento em que alguns alunos mencionam o resultado que esses professores obtiveram em sua aprendizagem: desenvolvimento do pensamento crítico e reflexivo (6), construção do conhecimento com o aluno (1), permitir que o aluno "absorva" o conhecimento (2) e saber explorar o potencial do aluno e fazê-lo se desenvolver (2).

Aqui, outra informação contextual se faz necessária. Grande parte destes estudantes estava, no momento da realização da presente pesquisa, começando a tomar contato com o conteúdo da didática e ainda não tinham tido temáticas relativas a processos de aprendizagem (estudantes de quarto período). Assim, ainda não tinham sido "alertados", se assim podemos dizer, para as questões relativas à íntima relação ensino e aprendizagem que fazem parte da compreensão e da prática docente. 
Do conjunto de nossa amostragem, oito alunos destacaram a importância do professor ser exigente, rigoroso e de promover disciplina em sala. Pela análise qualitativa dos dados, observamos que os alunos relacionam 0 rigor e a disciplina ao comprometimento do professor com sua atividade e à possibilidade de conseguir extrair o melhor de seus alunos. Bastante interessante foi a resposta de um aluno que mencionou o fato do professor ser "rigoroso e flexível". Num primeiro momento, esta afirmação pode parecer um contrassenso, mas não o é, uma vez que fica bem claro na visão dos alunos que rigor não é sinônimo de rigidez.

Este item nos remete ao ponto seguinte da análise, classificado em terceiro lugar em nosso levantamento: relacionamento com o aluno (com 22 referências). Esta categoria, marcada por termos como empatia, tato, compreensão, respeito, amizade, relação horizontal e "semelhança entre o que o professor é dentro e fora da sala", alia-se bastante a características pessoais consideradas desejáveis, perfazendo o perfil do que é ser, nos dizeres de um aluno, "um profissional humanizado". Assim, se unirmos o relacionamento com o aluno a algumas das características pessoais citadas e diretamente ligadas a fatores de relacionamento interpessoal, como ter postura flexível (6), ter paciência (5), ser justo (2), ser aberto ao diálogo (2), ter bom humor (2), ser humilde, simples e simpático (com uma citação cada), além do bom relacionamento extrassala (3), podemos observar que os aspectos relativos ao bom relacionamento com o aluno se sobressaem até em relação ao domínio do conteúdo, perfazendo um total de 42 citações. Este aspecto corrobora a pesquisa realizada por Pachane (2007, p. 191), ao referir-se à importância do que chamou de dimensão afetiva do fazer docente.

Do resultado desta parte da pesquisa talvez possamos dizer que ter domínio de conteúdo é algo inerente ao professor universitário, uma vez que-de modo geral - é mestre ou doutor em sua área e passou por um concurso no qual o domínio do conhecimento específico é fortemente avaliado. O que destaca, portanto, aquele que é o melhor professor (e não apenas um bom professor) é o seu caráter de "profissional humanizado" - utilizando os termos empregados por um aluno - são suas características pessoais e de relacionamento interpessoal, ao lado de sua habilidade para fazer uma boa aula.

Antes de finalizarmos a análise dos dados, é necessário mencionarmos aspectos relacionados com o envolvimento do professor com seu fazer docente, com o comprometimento com o curso e com os alunos (7 citações), bem como o respeito ao horário de aulas e assiduidade (3 citações), numa valorização da docência nem sempre possível no contexto da educação superior, marcada pelo predomínio de atividades de pesquisa e pela sobrecarga de atividades, como analisado por Pachane (2007).

Por fim, resta-nos atentar para o fato de que apenas dois alunos destacaram como características marcantes de seus professores o fato de terem 


\section{Graziela Giusti Pachane}

distinção em outros aspectos da vida acadêmica do docente, como ser um bom profissional (1) ou estar envolvido em projetos de pesquisa e extensão (1); apenas um aluno destacou o fato do professor ter amplo conhecimento geral e três referiram-se ao fato de que sua escolha do bom professor foi influenciada pelo fato de identificar-se com o conteúdo da disciplina.

\section{Considerações finais}

Buscamos, no decorrer do presente artigo, apresentar quais seriam as características distintivas do melhor professor universitário segundo a visão de licenciandos de diferentes cursos de uma universidade federal de Minas Gerais. Este estudo nos abre, por um lado, a perspectiva de compreensão do perfil desejado de um professor universitário e, por outro, novos questionamentos que dizem respeito, em especial, ao fato de tratarmos do professor considerado como o melhor formador de formadores.

Como salientado anteriormente, os textos que nos serviram de base perpassam as décadas de 1990 e de 2000. Cada autor apresenta um conjunto de características que, por si só, já ofereceriam material para um estudo detaIhado no sentido de buscarmos criar categorias exaustivas (BARDIN, 2008) que englobassem os itens mencionados por cada um deles. No entanto, tememos que a realização dessa tarefa, no momento, se mostre inócua.

Assim, propomo-nos a concluir apontando as características que se sobressaem ao buscarmos construir o perfil de um bom docente universitário, levando em conta tanto o material proposto pela literatura quanto os dados levantados com os estudantes. São elas: 1) a construção de uma boa aula; 2) características pessoais que permitam bom relacionamento interpessoal; 3) amplo domínio de conteúdo; 4) habilidades de comunicação; 5) preocupação com a aprendizagem do aluno; 6) comprometimento com a atividade docente em todas as suas dimensões e 7) distinção em termos de conhecimento geral ou atividades de pesquisa e extensão.

Em termos de novos questionamentos que este estudo suscita, podemos elencar: qual a compreensão de didática que os licenciandos conscientemente possuem (se questionados diretamente)? Essa compreensão se altera após o contato com disciplinas pedagógicas? Qual é o impacto do perfil desses docentes, considerados os melhores, no futuro trabalho dos licenciandos, no sentido de se constituírem como modelos de conduta profissional desses alunos? Como os próprios docentes se veem na condição de educadores? Quais os pressupostos que fundamentam suas práticas? Quem foram os seus melhores professores? Influenciaram essa prática que hoje realizam?

Enfim, são inúmeras questões que permanecem em aberto como convite à continuidade deste diálogo que, embora se some a vozes que já ecoam desde o final da década de 1980, apenas (re)iniciamos com o presente artigo. 
Quem é seu melhor professor universitário e por quê? Características do bom professor universitário sob o olhar de licenciandos

\section{Referências}

ANASTASIOU, L. das G. C.; ALVES, L. P. (Org.). Processos de Ensinagem na Universidade. Joinville, Univille, 2003.

BARDIN, L. Análise do conteúdo. 4 ed. Lisboa: Edições Setenta, 2008.

BENEDITO, A. V; FERRER, V.; FERRERES, V. La Formación universitária a debate. Barcelona: Publicaciones Universitat de Barcelona, 1995.

CHAUÍ, M. Escritos sobre a universidade. São Paulo: Editora da UNESP, 2001.

CUNHA, M. I. da. O bom professor e sua prática. Campinas: Papirus, 1989. J. M. 1998

O professor universitário na transição de paradigmas. Araraquara:

DINHAM, S. M. What college teachers need to know. In: MENGES, R. J.; WEIMER, M. (ed.). Teaching on solid ground: using scholarship to improve practice. San Francisco: Jossey-Bass, 1996.

FRANCO, B. Análise de conteúdo. 2. ed. Brasília: Líber Livro, 2005.

LEITE, C. (Org.). Sentidos da pedagogia no Ensino Superior. Porto: CIEE: Livpsic, 2010.

MARCELO GARCÍA, C. Formação de professores: para uma mudança educativa. Porto: Porto Ed, 1999.

PACHANE, G. G. A importância da formação pedagógica para o professor universitário. Rio de Janeiro: Sotese, 2007.

Formação de docentes universitários frente a um mundo em transformação. In: ISAIA, S. M. de A.; BOLZAN, D. P. de V. Pedagogia universitária e desenvolvimento profissional docente. Porto Alegre: EdiPUCRS, 2009.

PIMENTA, S. G.; ANASTASIOU, L. das G. C. Docência no Ensino Superior. São Paulo: Cortez, 2002.

PIMENTEL, M. da G. O professor em construção. Campinas: Papirus,1993.

RODRIGUES, M. E. F. Resgatando espaços e construindo ideias: ForGrad 1997. Rio de Janeiro: EdUFF, 2002.

\section{Correspondência}

Graziela Giusti Pachane - Rua Cândida Mendonça Bilharinho, 621, apto. 102 BI. 02. Uberaba, Minas Gerais.

Email: grazielagp@yahoo.com.br

Recebido em 22 de abril de 2011

Aprovado em 03 de março de 2012 